\title{
Assessment of population exposure to PM10 for respiratory disease in Lanzhou (China) and its health-related economic costs based on GIS
}

\author{
Zhaobin Sun ${ }^{1,2+}$, Xingqin $\mathrm{An}^{2 *}$, Yan $\mathrm{TaO}^{3+}$ and Qing $\mathrm{Hou}^{2+}$
}

\begin{abstract}
Background: Evaluation of the adverse health effects of $\mathrm{PM}_{10}$ pollution (particulate matter less than 10 microns in diameter) is very important for protecting human health and establishing pollution control policy. Population exposure estimation is the first step in formulating exposure data for quantitative assessment of harmful $\mathrm{PM}_{10}$ pollution.

Methods: In this paper, we estimate $\mathrm{PM}_{10}$ concentration using a spatial interpolation method on a grid with a spatial resolution $0.01^{\circ} \times 0.01^{\circ}$. $\mathrm{PM}_{10}$ concentration data from monitoring stations are spatially interpolated, based on accurate population data in 2000 using a geographic information system. Then, an interpolated population layer is overlaid with an interpolated $\mathrm{PM}_{10}$ concentration layer, and population exposure levels are calculated. Combined with the exposure-response function between $\mathrm{PM}_{10}$ and health endpoints, economic costs of the adverse health effects of $\mathrm{PM}_{10}$ pollution are analyzed.

Results: The results indicate that the population in Lanzhou urban areas is distributed in a narrow and long belt, and there are relatively large population spatial gradients in the XiGu, ChengGuan and QiLiHe districts. We select threshold concentration $C_{0}$ at: $0 \mu \mathrm{g} \mathrm{m}^{-3}$ (no harmful health effects), $20 \mathrm{\mu g} \mathrm{m}^{-3}$ (recommended by the World Health Organization), and $50 \mathrm{mg} \mathrm{m}^{-3}$ (national first class standard in China) to calculate excess morbidity cases. For these three scenarios, proportions of the economic cost of $\mathrm{PM}_{10}$ pollution-related adverse health effects relative to GDP are $0.206 \%, 0.194 \%$ and $0.175 \%$, respectively. The impact of meteorological factors on $\mathrm{PM}_{10}$ concentrations in 2000 is also analyzed. Sandstorm weather in spring, inversion layers in winter, and precipitation in summer are important factors associated with change in $\mathrm{PM}_{10}$ concentration.

Conclusions: The population distribution by exposure level shows that the majority of people live in polluted areas. With the improvement of evaluation criteria, economic damage of respiratory disease caused by $\mathrm{PM}_{10}$ is much bigger. The health effects of Lanzhou urban residents should not be ignored. The government needs to find a better way to balance the health of residents and economy development. And balance the pros and cons before making a final policy.
\end{abstract}

Keywords: $\mathrm{PM}_{10}$, Population exposure assessment, Economic assessment, Generalized additive model (GAM), GIS method

\footnotetext{
* Correspondence: anxq@cams.cma.gov.cn

${ }^{\dagger}$ Equal contributors

${ }^{2}$ Chinese Academy of Meteorological Sciences, China Meteorological

Administration, Beijing 100081, China

Full list of author information is available at the end of the article
} 


\section{Background}

The emission of harmful atmospheric pollutants, such as nitrogen oxides, sulfur oxides, soot, dust, smoke and other suspended particulate matter, can harm human health. The World Health Organization (WHO) has found that there are more than 2.7 million deaths worldwide attributable to air pollution each year [1]. Air pollution has become one of the most visible environmental problems in China, because of massive coal combustion with inadequate emission controls (Wang and [2] and motor vehicle emissions. Also, natural sources such as sandstorms are important, especially in North China, such as the area around Lanzhou [3-6].

In Europe and in the United States, suspended PM is recognized as the most important air pollutant in terms of human health effects [7]. Air pollution levels in developed countries have decreased dramatically in recent decades. In 2004, a study was done to assess the health impacts of by $\mathrm{PM}_{10}$ pollution (less than 10 microns in diameter) in 111 key Chinese cities. None of these cities have attained the national first class ambient air quality standard, and over half currently exceed the national second class standard, The total economic cost caused by PM10 pollution was estimated as approximately USD 29,178.7 million [8]. Serious $\mathrm{PM}_{10}$ levels are prevalent in many cities of China. PM is the most important air pollutant in the northern part of the country [9].

Numerous epidemiological studies indicate that both long- and short-term exposure to atmospheric PM, especially $\mathrm{PM}_{10}$, are associated with increases in mortality and morbidity [10-14]. Young children, the elderly, individuals with predisposed diseases, such as cardiovascular and pulmonary diseases, and workers in certain industries may be at higher risk. This is because of their increased biological sensitivities and different exposure patterns $[15,16]$. The relative risks of PM10 were 1.045 for population with the age less than 15-year-old, 1.033 for population with the age more than 65-year-old, 1.023 for male, 0.990 for female and 1.011 for population with the age between 15-year-old and 65-year-old [17].

Association with air pollution has been studied for a range of diseases, such as asthma, lung irritation, bronchitis, pneumonia, premature death and heart disease [15-22]. Zanobetti et al. [23] examined the association between $\mathrm{PM}_{10}$ and hospital admissions for heart and lung disease in 10 cities in the United States. They found a $2.5 \%$ (95\% confidence interval (CI): 1.8-3.3\%) increase in chronic obstructive pulmonary disease, a $1.95 \%(95 \%$ CI: $1.5-2.4 \%$ ) increase in pneumonia, and a $1.27 \%$ increase (95\% CI: $1-1.5 \%$ ) in cardiovascular disease for a $10 \mu \mathrm{g} \mathrm{m}^{-3}$ increase in $\mathrm{PM}_{10}$. Wellenius et al. [24] analyzed the association between $\mathrm{PM}_{10}$ and congestive heart failure in seven US cities. The APHEA 2 (Air Pollution on Health: European Approach) project investigated short-term health effects of particles in eight European cities. This study confirmed that particle concentrations in these cities were positively associated with increased numbers of admissions for respiratory diseases [25]. The evidence of adverse health effects related to $\mathrm{PM}_{10}$ is consistent with various cities in China. This is even more important in China because of its severe $\mathrm{PM}_{10}$ pollution levels and associated high population densities. Many studies in Chinese cities have shown health effects on mortality and morbidity associated with exposure to PM similar to studies in Europe and America. The "Impact of Air pollution on Children's Lung Function" study is a Sino-US scientific and technological collaboration. Three size fractions of PM $\left(\mathrm{PM}_{2.5}, \mathrm{PM}_{2.5-10}\right.$, and $\left.\mathrm{PM}_{10}\right)$ were measured in schoolyards at eight elementary schools in four large Chinese cities (Guangzhou, Wuhan, Lanzhou, Chongqing) during 1995 and 1996. The results gave significant evidence that there were positive associations between outdoor PM levels and pediatric respiratory symptoms [26]. Using factor analysis with varimax rotation, sources of fine and coarse airborne PM in the four cities were examined. The contribution to coarse PM ( $\left.\mathrm{PM}_{2.5-10}\right)$ from crustal factors is greater than that to fine $P M$ $\left(\mathrm{PM}_{2.5}\right)$ [27].

Relevant research has been done in Chinese cities such as Shanghai [28], Beijing [29-31], Wuhan [32] and Hong Kong [33]. Lanzhou is expanding and there is an influx of population from the rural areas and urban fringe to the core of the city. Air quality in the city has been deteriorating, resulting in one of the most serious pollution problems nationally [34-36]. For Lanzhou, quantitative evaluation of the adverse health effects of $\mathrm{PM}_{10}$ pollution is becoming critical to optimizing the energy structure, controlling total emission of air pollutants, and the treatment of automobile exhaust. Referencing to the related epidemiological literature published around the world in recent years, Hou et al. screens out the $\mathrm{PM}_{10}$ health endpoints and appropriate exposure-response coefficients, and calculates the health economic loss by $\mathrm{PM}_{10}$ of Lanzhou during 2002-2009. But there is a hypothesis the uniform distribution of $\mathrm{PM}_{10}$. In fact, it is the uneven distribution, so the health economic loss by $\mathrm{PM}_{10}$ of Lanzhou is calculated under this scenario.

The present work, based on ESRI ArcGIS Server 9.2 (Geographic information system) spatial information analysis function, assesses the harmful health effects of $\mathrm{PM}_{10}$ pollution in Lanzhou using monitoring and population data. To provide a more detailed picture of exposure, population exposure levels are estimated by combining $\mathrm{PM}_{10}$ spatial distribution with that of population. We selected the generalized additive model (GAM), run with $R$ software, to determine health effects of $\mathrm{PM}_{10}$ on morbidity rates and to establish an exposure-response function for $\mathrm{PM}_{10}$. Economic costs of adverse health effects related to 
$\mathrm{PM}_{10}$ are also calculated. The results can serve as a useful reference for health risk management, and as a scientific basis for reducing economic loss and policy making regarding air pollution control.

\section{Methods}

\section{$\mathrm{PM}_{10}$ data collection}

This case study is for Lanzhou, the capital of Gansu Province and an industrial and oil processing city in northwest China. Lanzhou is surrounded by high mountains; the frequency of calm winds is as much as $75 \%$, and $87 \%$ in winter. Temperature inversions occur year round. Such inversions, calm winds, and a continuously stratified atmosphere are not conducive to horizontal and turbulent diffusion within basins [37].

Total suspended particulate (TSP) concentration data from monitoring stations were taken from the Project of "Science and Technology Cooperation Project of the Chinese Academy of Science and Gansu Province". Seven ambient air quality monitoring stations were distributed relatively across the Lanzhou urban area, including the XiGu, ChengGuan, AnNing, and QiLiHe districts. All stations made measurements in 2000. Because the Project did not include direct measurements of $\mathrm{PM}_{10}$ concentrations, a conversion factor between TSP and $\mathrm{PM}_{10}$ was used. The distribution of the seven stations and four hospitals is shown in Figure 1. The conversion

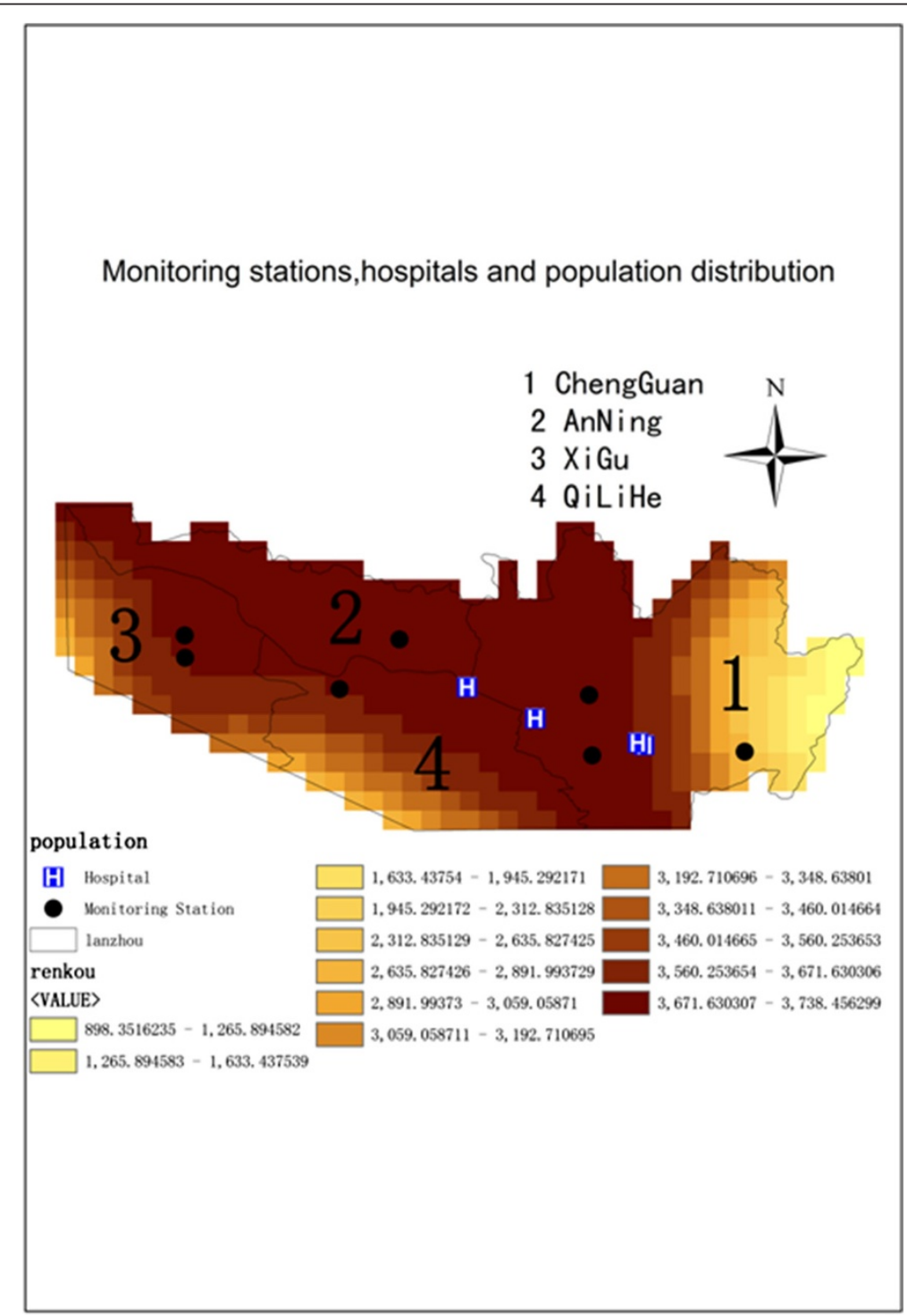

Figure 1 Total suspended particles (TSP) monitoring stations, four hospitals and population distribution in the Lanzhou urban areas during 2000 (The units are number of people per $\mathrm{km}^{2}$ ) in Lanzhou urban areas (China) during 2000. 
factor chosen is similar to that proposed by Dockery et al. [38]. The $\mathrm{PM}_{10}$ concentration is calculated as

$$
\mathrm{PM}_{10}=\mathrm{TSP} \times 0.55
$$

The $\mathrm{PM}_{10}$ concentration data were used for calculation of daily exposure and population-weighted concentration.

\section{Population data for Lanzhou}

Data of the Gridded Population of the World version 3 (GPWv3) from the Center for International Earth Science Information Network (CIESIN) of Columbia University and Centro Internacional de Agricultura Tropical (CIAT) were used as basic population data. GPWv3 is the latest update of the GPW dataset. Earlier versions and GPWv3 have been extensively used in global population studies [39-41].

\section{Data for fitting of GAM}

We obtained daily $\mathrm{SO}_{2}, \mathrm{NO}_{2}$ and $\mathrm{PM}_{10}$ concentration data from the Lanzhou Environmental Monitoring Station. These daily data cover the 5 years from 2001 to 2005 . The meteorological data are daily maximum, minimum and average temperature, daily atmospheric pressure and relative humidity, and were provided by the Lanzhou Meteorological Bureau. These data are also from 2001 to 2005. Hospital admissions data of respiratory system diseases are from the four largest comprehensive hospitals in the Lanzhou urban area.

\section{Morbidity data}

Hospital admissions data of respiratory system diseases are considered as health endpoints. Lacking access to data of morbidity rate of respiratory system diseases in Lanzhou, this rate is calculated in accord with ratios of national hospital admissions for respiratory system diseases from the Chinese Ministry of Health. Methods International classification (ICD-10) was adopted to provide the scientific basis for statistical analysis to calculating the disease composition. Specific classification standard is ICD-10:J00-99. Diseases of the information collected are from each hospital database.

\section{Calculation of daily exposure and population-weighted concentration}

Based on the GIS, $\mathrm{PM}_{10}$ concentration data from the seven monitoring stations were spatially interpolated, using kriging spatial interpolation. $\mathrm{PM}_{10}$ concentrations were calculated at resolution $0.01^{\circ} \times 0.01^{\circ}$, approximately $1 \mathrm{~km} \times 1 \mathrm{~km}$. Population data were also spatially interpolated, to attain the high spatial resolution $\left(0.01^{\circ} \times 0.01^{\circ}\right)$ matching that of $\mathrm{PM}_{10}$ concentration data. Using the GIS spatial information analysis function, the population and $\mathrm{PM}_{10}$ concentration layers (total of 475 grid points) were overlaid to analyze population exposure levels in various concentration ranges.

Figure 1 shows that the four districts of the Lanzhou urban area are all densely populated. Population of the ChengGuan district is more concentrated, followed by AnNing, QiLiHe district and XiGu districts, which are all distributed in a narrow, long belt. There are 43 grids, over which population density ranged from $800 \mathrm{~km}^{-2}$ to $2700 \mathrm{~km}^{-2}$ mainly in the eastern ChengGuan district. Average population density is greater than $3700 \mathrm{~km}^{-2}$ mainly in the AnNing and western ChengGuan districts with 213 grids, comprising $45 \%$ of the total grid. In the XiGu and QiLiHe districts, spatial gradients of population density are relatively large, and the direction is northwest-southeast. The gradient in the ChengGuan district is east-west.

We also calculated the population-weighted exposure level (PWEL). Given grid i, the population weighted exposure equation is as follows:

$$
\text { PWEL }=\sum\left(\mathrm{P}_{\mathrm{i}} \times \mathrm{C}_{\mathrm{i}}\right) / \sum \mathrm{P}_{\mathrm{i}},
$$

where $P_{i}$ is the population in grid $i$, and $C_{i}$ is its average $\mathrm{PM}_{10}$ concentration.

Figure 2(a) reveals that $\mathrm{PM}_{10}$ concentrations in most Lanzhou urban areas are between 0.31 and $0.35 \mathrm{mg} \mathrm{m}^{-3}$ before weighting. Therefore, the population within grids with $\mathrm{PM}_{10}$ concentration between 0.31 and $0.35 \mathrm{mg} \mathrm{m}^{-3}$ has the greatest exposure. After population weighting (Figure 2(b)), we see the following results. There are 140,000 people exposed to between $0.28 \mathrm{mg} \mathrm{m}^{-3}$ and $0.31 \mathrm{mg} \mathrm{m}^{-3}$, more than 150,000 exposed to between $0.31 \mathrm{mg} \mathrm{m}^{-3}$ and $0.34 \mathrm{mg} \mathrm{m}^{-3}$, more than 270,000 exposed to between $0.34 \mathrm{mg} \mathrm{m}^{-3}$ and $0.37 \mathrm{mg} \mathrm{m}^{-3}$, and more than 60,000 people exposed to between $0.37 \mathrm{mg} \mathrm{m}^{-3}$ and $0.41 \mathrm{mg} \mathrm{m}^{-3}$. The grid average of $\mathrm{PM}_{10}$ concentration in all areas is $0.329 \mathrm{mg} \mathrm{m}^{-3}$, and the population-weighted average is $0.345 \mathrm{mg} \mathrm{m}^{-3}$, an increase of nearly $5 \%$. With population weighting, there are more people living in more polluted areas. Consequently, it is more realistic to use the population-weighting algorithm for determining population exposure to $\mathrm{PM}_{10}$ concentration.

\section{Fitting of GAM}

The GAM was originally described by Hastie and Tibshirani $[42,43]$, and has been applied in a variety of research fields. In time series studies, the GAM was used to adjust for potential confounders of seasonality, trends, and weather variables in epidemiological analyses of mortality. Here, the $m g c v$ package with R2.6 [44] was used to assess the relationship between the daily $\mathrm{PM}_{10}$ concentration and daily hospital admissions for respiratory diseases. GAM was set up based on the above package, which is largely based on Hastie [42,43]. This 

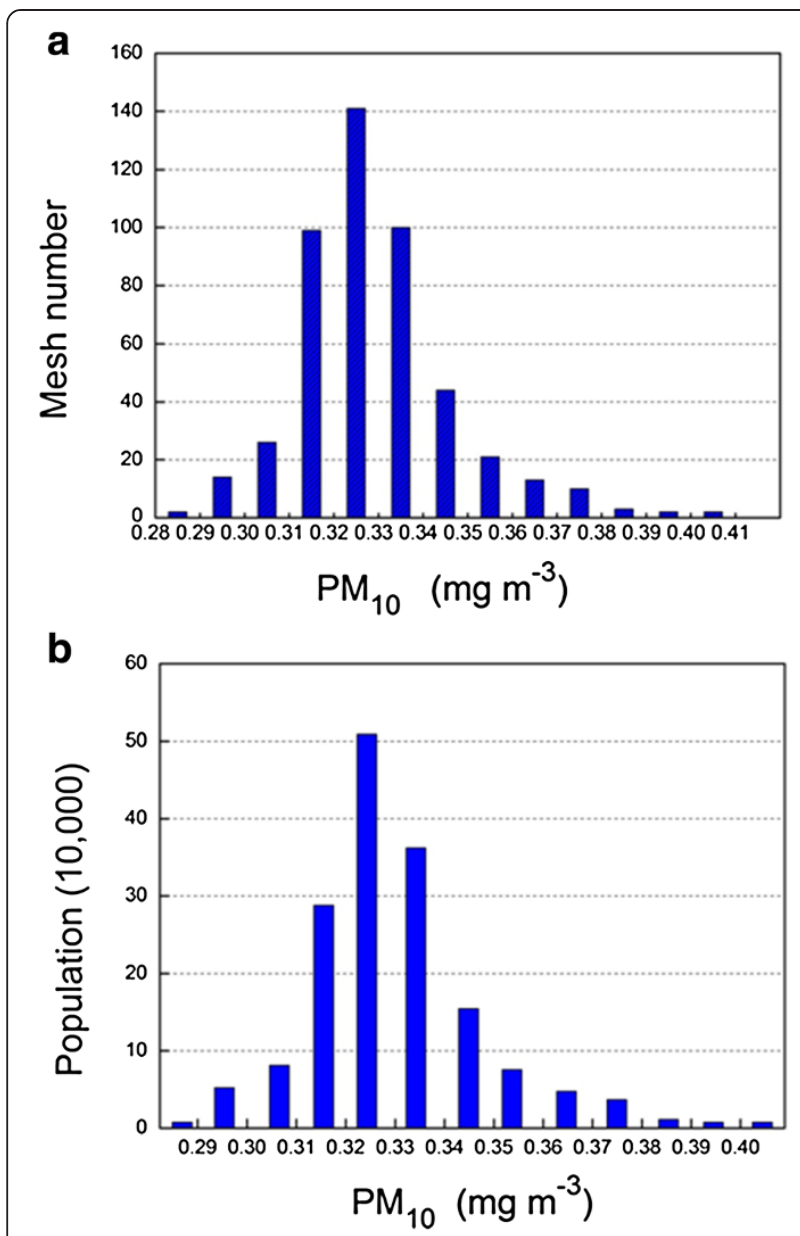

Figure 2 Population exposure level in Lanzhou urban areas for $\mathrm{PM}_{10}$ (a) Mesh number in different $\mathrm{PM}_{10}$ concentration intervals. (b) Frequency distribution of population weighted exposure concentrations.

package has an advantage in terms of computational time, and is used when the database is large.

The Akaike information criterion (AIC) was proposed by Akaike in 1973. A smaller AIC is characteristic of a model with better fit. We selected the best form of the model by minimizing AIC [42], which is achieved by adjustment of the degrees of freedom $(d f)$.

The GAM fitted to the respiratory admission time series $Y_{k}$, under the assumption of Poisson counts and a log-link function for predetermined lags is

$$
\begin{aligned}
\log \left[\mathrm{E}\left(\mathrm{Y}_{\mathrm{k}}\right)\right]= & \alpha+\mathrm{DOW}+\beta \mathrm{PM}_{10} \\
& +\mathrm{s}(\text { time, } \mathrm{df})+\mathrm{s}\left(\mathrm{Z}_{\mathrm{k}}, \mathrm{df}\right)
\end{aligned}
$$

In this equation, $\alpha$ denotes some constant, $\beta$ the exposure-response coefficient of $\mathrm{PM}_{10}$, and $\mathrm{s}(\mathrm{)}$ the smoothing spline function for optimum flexibility when modeling the confounders. DOW is a dummy variable of weekday effect, and time is calendar time. $d f$ is an adjustable variable according to various results for the AIC.

Maximum, minimum and average temperature, daily atmospheric pressure and relative humidity are considered confounders. DOW, time, maximum temperature, daily atmospheric pressure and $\mathrm{PM}_{10}$ concentration are involved in the GAM, toward obtaining the AIC. The results are significant when adding other factors makes no difference in fitting the GAM. When the AIC value calculated by different models with various factors can no longer be diminished, the result is the final model.

\section{Exposure-response function}

The exposure-response function is often used in epidemiological studies to relate air pollution and adverse health outcomes. For the exposure population, disease or death is a small-probability event following a Poisson distribution.

$$
\mathrm{E}-\mathrm{E}_{0} \exp \left[\beta\left(\mathrm{C}-\mathrm{C}_{0}\right)\right]
$$

Morbidity and excess mortality caused by a certain type of pollutant is calculated as

$$
\mathrm{N}=\mathrm{P}\left(\mathrm{E}-\mathrm{E}_{0}\right)=\mathrm{PE}\left(1-1 / \exp \left[\beta\left(\mathrm{C}-\mathrm{C}_{0}\right)\right]\right)
$$

In Equations (4) and (5), $\beta$ (per $1 \mu \mathrm{g} \mathrm{m}^{-3}$ ) is the exposure-response coefficient; $\mathrm{C}$ is $\mathrm{PM}_{10}$ concentration $\left(\mu \mathrm{g} \mathrm{m}^{-3}\right) ; C_{0}$ is threshold concentration $\left(\mu \mathrm{g} \mathrm{m}^{-3}\right) ; \mathrm{E}(\%)$ and $\mathrm{E}_{0}$ (\%) are corresponding health effects $\mathrm{C}$ and $\mathrm{C}_{0}$; $\mathrm{P}$ (persons) is exposure population; and $\mathrm{N}$ (persons) is morbidity or excess mortality numbers caused by a certain type of pollutant. E can be derived if data are available for $\beta, C, C_{0}$, and $E_{0}$. The exposure-response function is a quantitative functional relation between the variation of $\mathrm{PM}_{10}$ and health endpoint. The difficulty of establishing this function is choosing $\beta$ and $C_{0}$. Here, $\beta$ is calculated with the GAM. It was shown in an Australian study [45] that although levels of particulate air pollution in Sydney were low, PM pollution was consistently associated with both daily mortality and hospital admissions. There was no deterministic threshold concentration for health effects presented. In this work, we chose three threshold concentrations to evaluate economic costs of the adverse health effects of $\mathrm{PM}_{10}$ pollution. The WHO report "Air Quality Guidelines Global Update 2005" has indicated that no matter how low PM concentration was, it could harm human health [46]. As a result, zero $\left(\mathrm{mg} \mathrm{m}^{-3}\right)$ was chosen as the $\mathrm{PM}_{10}$ threshold concentration, used to calculate "no harmful health effects." We also used the second threshold concentration recommended by the WHO, $20 \mu \mathrm{g} \mathrm{m}^{-3}$. The national first class standard in China, $50 \mu \mathrm{g} \mathrm{m}^{-3}$, was used as the third. Because $C_{0}$ is a very important and sensitive parameter in estimating the health effect of 
pollutants, the purpose of selecting different ones was to ensure evaluation objectivity. Economic losses were determined for $C_{0}$ at $0 \mu \mathrm{g} \mathrm{m}^{-3}, 20 \mu \mathrm{g} \mathrm{m}^{-3}$ and $50 \mu \mathrm{g} \mathrm{m}{ }^{-3}$.

\section{Determining economic costs of adverse health effects}

Once the relationship between $\mathrm{PM}_{10}$ concentration and health effects is established, the next stage requires assessment of economic costs versus those predicted based on health effects. Based on the GIS, average daily cases of respiratory disease caused by $\mathrm{PM}_{10}$ on the $0.01^{\circ} \times$ $0.01^{\circ}$ grid can be calculated according to $\beta$ (exposure-response coefficient) and actual incidence rate of the disease. Total cases of the disease are obtained by summing daily cases over an entire year.

There are no results for cost of pollution-related health effects for inpatients and outpatients in China using the willingness to pay approach, so the cost of illness (COI) is used to estimate economic costs of adverse health effects of $\mathrm{PM}_{10}$ pollution.

$$
\begin{aligned}
& \mathrm{P}=\mathrm{fp}=\mathrm{ft} \\
& \mathrm{P}=\mathrm{fp}(1+\triangle \mathrm{C} \beta) \\
& \mathrm{P}=\mathrm{fp}(\triangle \mathrm{C} \beta /(1+\triangle \mathrm{C} \beta))
\end{aligned}
$$

$\mathrm{P}$ is super hospital visitors under the present air pollution levels; fp is hospital visitors, under the present air pollution levels from China health statistics yearbook; $\mathrm{ft}$ is clean thick degree level in the hospital; $\beta$ is the exposure-response coefficient; $\triangle \mathrm{C}$ is the difference between the health hazard pollutants concentration threshold and actual pollutant concentration.

\section{Results}

Based on the GIS spatial information analysis function, health effects of $\mathrm{PM}_{10}$ in Lanzhou were evaluated by use of monitoring and population data. Population data were spatially interpolated to attain the higher spatial resolution matching that of $\mathrm{PM}_{10}$ concentration data. The results indicate that air in Lanzhou is seriously polluted by $\mathrm{PM}_{10}$ in winter and spring, which would greatly impair human health and produce more health-related economic costs. In evaluating these costs, results varied with the calculation scenario.

The $95 \%$ confidence limit of $\beta$ is $[\beta \pm 1.96 \mathrm{SE}$ (standard error $\mathrm{SE}$ )] and $\mathrm{PM}_{10}$ lag 4 is significantly related to respiratory system disease $(\beta=0.197$; $\mathrm{SE}=0.061 ; 95 \%$ confidence limit $0.317-0.077$ ). Because dust is the main component of $\mathrm{PM}_{10}$ in Lanzhou, toxicity is relatively low. Although $\mathrm{PM}_{10}$ concentration is high, the exposure response relation coefficient (RR) is relatively small, as shown in Table 1. The smallest RR is 1.009(1.006-1.013) and biggest is $1.020(1.015-1.024)$. RR for a $10 \mu \mathrm{g} \mathrm{m}^{-3}$ increase of $\mathrm{PM}_{10}$ in Lanzhou is between 1.002 and 1.003.

Cases in different scenarios for $\mathrm{C}_{0}$ were calculated using Equation (5), and the 95\% confidence limit is given in Table 2. The results show that the excess number of patients decreased with $\mathrm{C}_{0}$ increase. This indicates that the excess number of patients is sensitive to the selection of $\mathrm{C}_{0}$, as are total costs. When the threshold concentration is relatively high, the proportion of economic costs for $\mathrm{PM}_{10}$ to the GDP is large.

We calculated coefficients of correlation between the seven monitoring stations. The $\mathrm{PM}_{10}$ time series of Wen Hua Gong station was used to investigate temporal variation. Its correlation coefficient with other stations was as high as 0.83 (above 99\% confidence level), indicating satisfactory representation of the Lanzhou urban area.

Lanzhou is within the Hexi Corridor, in an inland arid or semi-arid area of China. It is one of the most polluted cities in the country. Figure 3 shows that $\mathrm{PM}_{10}$ concentration in Lanzhou peaks in April and December. Sandstorms frequently impact Hexi Corridor areas, and represent the greatest moving source of pollution for Lanzhou. In spring 2000, when precipitation was low and windy weather was caused by frequent activities of cold air, the topsoil was dry and could be readily blown away. These were all dynamic factors for sandstorm formation. Therefore, the peak in April was mainly caused by sandstorm-related weather; after spring, the $\mathrm{PM}_{10}$ concentration fell sharply. The minimum concentration was in August. The contribution of coal combustion for domestic heating to winter $\mathrm{PM}_{10}$ pollution was very marked, and released large amounts of harmful pollutant. Inversion layers near the ground and basin landforms were not conducive to horizontal and turbulent diffusion, and constituted the major reason for the peak in December.

Because Lanzhou is at the northern periphery of East Asian summer monsoon activity, precipitation is very irregular. In summer 2000, the East Asia trough strength-

\begin{tabular}{|c|c|c|}
\hline Case & $\mathbf{R R}$ & $95 \% \mathrm{Cl}$ \\
\hline Tacoma(Schwartz,1995) & 1.019 & $1.006 \sim 1.032$ \\
\hline Spokane(Schwartz,1996) & 1.016 & $1.007 \sim 1.026$ \\
\hline London(Atkinson,1999) & 1.010 & $1.004 \sim 1.016$ \\
\hline APHEA(Atkinson,2001) & 1.009 & $1.006 \sim 1.013$ \\
\hline USA(Zanobetti,2000) & 1.020 & $1.015 \sim 1.024$ \\
\hline Ontario(Schwartz,1995) & 1.012 & $1.008 \sim 1.016$ \\
\hline New York(Schwartz,1995) & 1.010 & $1.002 \sim 1.019$ \\
\hline New Haven(Schwartz,1995) & 1.012 & $1.000 \sim 1.025$ \\
\hline
\end{tabular}
ened and moved west, causing cold air to move southward and collide with warm air from the southern airstream of 
Table 2 Economic Evaluation in economic cost of health harming effecting by $\mathrm{PM}_{10}$ pollution under different scenarios of $\mathrm{C}_{0}$

\begin{tabular}{cccccccc}
\hline Scenario & Standard & $\begin{array}{c}\text { CO } \\
\left(\mu \mathbf{g ~ m}^{-3}\right)\end{array}$ & Cases & $\begin{array}{c}\text { Cost } \\
\text { (per-case) }(\$)\end{array}$ & Total cost (\$) & $\begin{array}{c}\text { GDP } \\
\text { (\$ in billions) }\end{array}$ & $\begin{array}{c}\text { GDP } \\
\text { Percentage (\%) }\end{array}$ \\
\hline A & zero & 0 & $9651.9(15230.5,3847.6)$ & 660 & $6370254(10052130,2539416)$ & 3.096 & 0.206 \\
B & WHO & 20 & $9083.9(14350.9,3616.9)$ & 660 & $5995440(9471594,2387154)$ & 3.096 & 0.194 \\
& Cational first-class & 50 & $8227.8(13021.1,3270.2)$ & 660 & $5430348(8593926,2158332)$ & 3.096 & 0.175 \\
\hline
\end{tabular}

the subtropical high, generating strong winds and extensive precipitation in Lanzhou. Therefore, the $\mathrm{PM}_{10}$ concentration was relatively low in June, July and August.

With consideration of available research findings and data, we chose COI as an economic evaluation method [47]. Given the sensitivity to $C_{0}$, we used three different levels for it to ensure evaluation objectivity.

For $\mathrm{C}_{0}$ of $0 \mu \mathrm{g} \mathrm{m}^{-3}, 20 \mu \mathrm{g} \mathrm{m}^{-3}$ and $50 \mu \mathrm{g} \mathrm{m}^{-3}$, the proportions of economic cost to GDP were $0.206 \%, 0.194 \%$ and $0.175 \%$ respectively. Thus, $\mathrm{PM}_{10}$ abatement is necessary. To reduce $\mathrm{PM}_{10}$ concentration in Lanzhou, cutting atmospheric pollutant emissions, planting surrounding mountains with greenery, and developing sandstorm monitoring and early-warning technology are all effective approaches.

\section{Discussion}

$\mathrm{C}_{0}$ is a sensitive parameter in estimating the health effect of pollutants, when the threshold concentration chosen relatively high, the economic costs of adverse health effects of $\mathrm{PM}_{10}$ pollution is low, when the selected threshold concentration is relatively low, the high economics cost of adverse health effects of $\mathrm{PM}_{10}$ pollution.

In establishing the exposure-response function, we used the GAM with $\mathrm{R}$ software to quantify the adverse health effects of $\mathrm{PM}_{10}$. Different models can produce varying estimates. We selected the GAM because it is more flexible, and allows nonparametric adjustments for nonlinear confounding affects of seasonality, the weekday effect and weather variables. Moreover, the $\mathrm{R}$ software was more computationally steady than S-Plus software.

We found that although $\mathrm{PM}_{10}$ concentrations are much higher in the Lanzhou urban area and the urban population their experiences much greater exposure than in other Chinese cities $[36,48,49]$, the exposureresponse coefficient $\beta$ is relatively small, suggesting weak sensitivity of the population in local areas. The population structure of Lanzhou is different from that of Europe and the United States where there is a larger aging population; the elderly are an easily affected group. Another reason may be that $\mathrm{PM}_{10}$ components are different from other areas. In developed countries and areas, the main particle pollution source is automobile

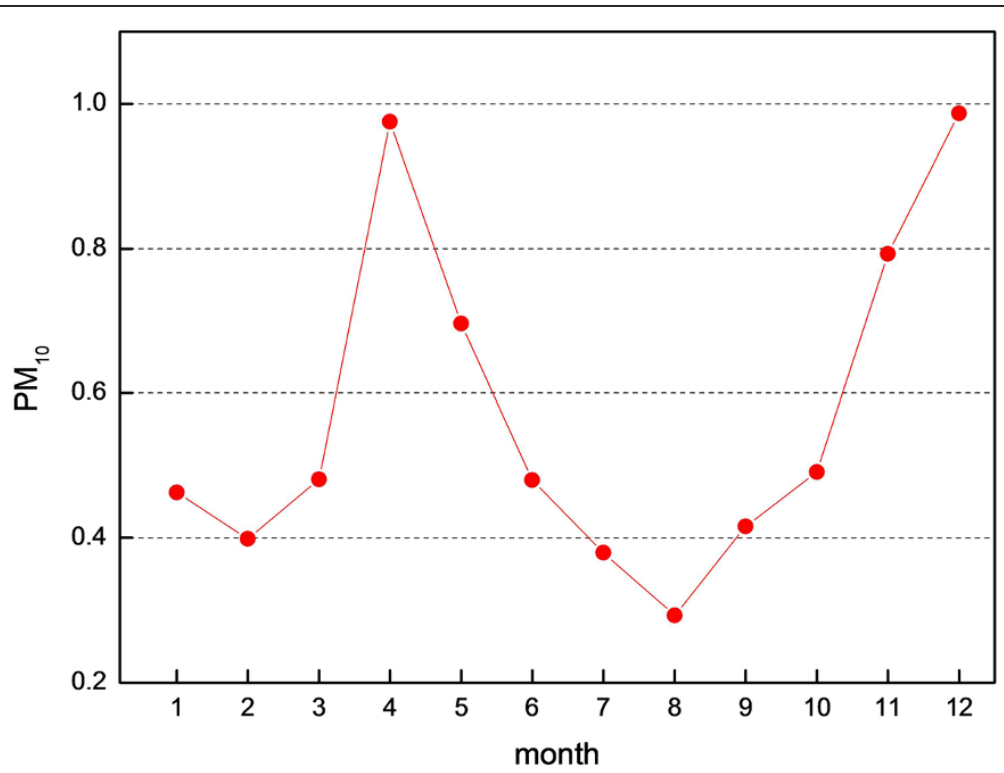

Figure $3 \mathrm{PM}_{10}$ concentration variation at the Wen Hua Gong station during 2000 (Unit:mg/m³). 
exhaust, which generates secondary particles that are more toxic than the $\mathrm{PM}_{10}$ of Lanzhou. Urban dust and sand have high proportions of local $\mathrm{PM}_{10}$ in the city, which are also less toxic.

The relationship of TSP and $\mathrm{PM}_{10}$ is quite different related to the source and it can be described in different equation. The constant conversion factor between TSP and $\mathrm{PM}_{10}$ due to the lack of direct $\mathrm{PM}_{10}$ measurement, the dismatch between the 2000 population data and the time period of hospital admissions (2001 to 2005), limited monitors(7 sites), and respiratory hospital admission from only four hospitals. it can also lead to uncertainty.

Current time series research on adverse health effects of air pollution in China is focused on "one point," i.e., it considers research areas as a single point. In fact, the relationship between $\mathrm{PM}_{10}$ concentration and population distribution can change over time and space. In this study, there were seven monitoring stations in the research area, and $\mathrm{PM}_{10}$ concentration data were interpolated by the GIS. We evaluated health effects related to $\mathrm{PM}_{10}$ and their economic costs. We transformed fixed-site pollution monitoring observation to a continuous surface. This is a predictive technique for $\mathrm{PM}_{10}$ concentrations in areas without observed data, causing inevitable data deviation. More monitoring sites and atmospheric pollution models for simulating pollutant concentration are useful means to decrease such deviation. Choi et al. [50] showed that health effects in some areas were more significant upon combining PM monitoring concentration data and Models-3 CMAQ (Community Multiscale Air Quality Modeling) simulated results for PM.

\section{Conclusions}

The average population-weighted $\mathrm{PM}_{10}$ concentration is $0.345 \mathrm{mg} \mathrm{m}^{-3}$ more than that without population weighting, an increase of nearly $5 \%$ from $0.329 \mathrm{mg} \mathrm{m}^{-3}$ to $0.345 \mathrm{mg} \mathrm{m}^{-3}$. Considering population spatial distribution in Lanzhou, there are larger population living in more polluted areas.

We select threshold concentration $C_{0}$ at: $0 \mu \mathrm{g} \mathrm{m}^{-3}$ (no harmful health effects), $20 \mu \mathrm{g} \mathrm{m}^{-3}$ (recommended by the World Health Organization), and $50 \mu \mathrm{g} \mathrm{m}^{-3}$ (national first class standard in China) to calculate excess morbidity cases. For these three scenarios, proportions of the economic cost of $\mathrm{PM}_{10}$ pollution-related adverse health effects relative to GDP are $0.206 \%, 0.194 \%$ and $0.175 \%$, respectively.

\section{Competing interests}

The authors declare that they have no competing interests.

\section{Authors' contributions}

ZS carried out the calculation of GAM model and participated in drafting the manuscript. XA participated in the design of the study and drafting the manuscript. YT participated in the GAM model calculation and the statistical analysis. QH participated in the calculation of health-related economic costs. All authors read and approved the final manuscript.

\section{Acknowledgements}

This research was supported by the Chinese Ministry of Science and Technology (2011CB403404) and the Natural Science Foundation of China (41005087, 40875086,41075102).

\section{Author details}

${ }^{1}$ Beijing Meteorological Observatory, Beijing 100089, China. ${ }^{2}$ Chinese Academy of Meteorological Sciences, China Meteorological Administration, Beijing 100081, China. ${ }^{3}$ College of Atmospheric Sciences, Lanzhou University, Lanzhou 730000, China.

Received: 18 March 2013 Accepted: 13 September 2013

Published: 27 September 2013

\section{References}

1. WHO: World Health Organization. WHO Guidelines for air Quality, Fact Sheet No.187. Available from: http://www.who.int/inffs/en/fact187.html, 2003, cited in February 14 ${ }^{\text {th }}, 2003$.

2. Wang XP, Mauzerall DL: Evaluating impacts of air pollution in china on public health: implications for future air pollution and energy policies. Atmos Environ 2005, 40:1706-1721.

3. Wang S, Dong GR, Chen HZ, Li XL, Jin J: Advances in studying sand-dust storms of China. J DES RES 2000, 20:349-356.

4. Ding RQ, Wang SG, Shang KZ, Yang DB: Tendency and interdecadal changes of spring dust storm in China. PLATEAU METEOROLOG 2004, 23:660-666.

5. Wang SG, Wang JY, Zhou ZJ, Shang KZ, Yang DB, Zhao ZS: Regional characteristics of dust events in China. ACTA GEOGR SIN 2003, 2:193-200.

6. Feng XY, Wang SG, Yang DB, Shang KZ: Influence of dust events on PM10 pollution in Key environmental protection cities of northern china during recent years. J DES RES 2011, 3:735-740.

7. El-Fadel M, Massoud M: Particulate matter in urban areas: health-based economic assessment. Sci Total Environ 2000, 257:133-146.

8. Zhang MS, Song Y, Cai XH, Zhou J: Economic assessment of the health effects related to particulate matter pollution in 111 Chinese cities by using economic burden of disease analysis. J Environ Manage 2008, 88:947-954

9. Tao Y: Physical and Chemical Characteristics of Atmospheric Particulate Matter and Their Impact on Human Health in Lanzhou. Dissertation, Lanzhou: Lanzhou University; 2009 (in Chinese).

10. Schwartz J: Air pollution and hospital admissions for heart disease in eight U.S. Counties. Epidemiology 1999, 10:17-22.

11. Kim H, Kim Y, Hong YC: The lag-effect pattern in the relationship of particulate air pollution to daily mortality in Seoul, Korea. Int $J$ Biometeorol 2003, 48:25-30.

12. Dockery DW, CA PIII, Xu X, Spengler JD, Ware JH, Fay ME: An association between air pollution and mortality in Six U.S. Cities. N Engl I Med 1993, 329:1753-1759.

13. Pope III, Krewski K, Pope CA III, Burnett RT, Thun MJ, Calle EE, Krewski D, Ito K, Thurston GD: Lung cancer, cardiopulmonary mortality, and long-term exposure to fine particulate air pollution. J Am Med Assoc 2002, 287(CA, RT Burnett, MJ Thun, EE Calle, D):1132-1141.

14. CA PIII, Thun MJ, Namboodiri MM, Dockery DW, Evans JS, Speizer FE, Jr Heath CW: Particulate air pollution as a predictor of mortality in a prospective study of U.S. Adults. Am J Respir Crit Care Med 1995, 151:669-674.

15. Chen BH, Kan HD: Air pollution and population health: a global challenge. Environ Health Prev Med 2008, 13:94-101.

16. Zeka A, Zanobetti A, Schwartz J: Short term effects of particulate matter on cause specific mortality: effects of lags and modification by city characteristics. Occup Environ Med 2005, 62:718-725.

17. Scoggins A, Kjellstrom T, Fisher G, Connor J, Gimson N: Spatial analysis of annual airpollution exposure and mortality. Sci Total Environ 2004, 321(1-3):71-85.

18. Katsouyanni $\mathrm{K}$, Coauthors: Confounding and effect modification in the short-term effects of ambient particles on total mortality: results from 29 European cities within the APHEA2 project. Epidemiology 2001, 12:521-531.

19. Kan HD, Coauthors: Differentiating the effects of fine and coarse particle on daily mortality in Shanghai, China. Environ Res 2007, 105:380-389. 
20. Metzger KB, Coauthors: Ambient air pollution and cardiovascular emergency department visits. Epidemiology 2004, 15:46-56.

21. Lee JT, Kim H, Hong YC, Kwon HJ, Schwartz J, Christiani DC: Air pollution and daily mortality in seven major cities of Korea, 1991-1997. Environ Res 2000, 84:247-254.

22. Samet JM, Dominici F, Curriero FC, Coursac I, Zeger SL: Fine particulate air pollution and mortality in 20 US cities,1987-1994. N Engl J Med 2000, 343:1742-1749.

23. Zanobetti A, Schwartz J, Dockery DW: Airborne particles are a risk factor for hospital admissions for heart and lung disease. Environ Health Perspect 2000, 108:1071-1077.

24. Wellenius GA, Schwartz J, Mittleman MA: Particulate air pollution and hospital admissions for congestive heart failure in seven United States cities. Am J Cardiol 2006, 97:404-408.

25. Atkinson RW, Coauthors: Acute effects of particulate air pollution on respiratory admissions results from APHEA 2 project. Am J Respir Crit Care Med 2001, 164:1860-1866.

26. Wei F, Teng E, Wu G, Hu W, Wilson WE, Chapman RS, Pau JC, Zhang J: Ambient concentrations and elemental compositions of PM10 and PM2.5 In four Chinese cities. Environ Sci Tech 1999, 33:4188-4193.

27. Wei $H$, Fusheng W: Factor analysis of elements in airborne particulate matter of the4Chinese cities. Environ Monit China 2003, 19:39-42 (in Chinese).

28. Kan HD, Chen BH: A case-crossover analysis of Air pollution and daily mortality in Shanghai. J Occu Health 2003, 45:119-124.

29. Zhang MS, Song Y, Cai XH: A health-based assessment of particulate air pollution in urban areas of Beijing in 2000-2004. Sci Total Environ 2007, 376:100-108.

30. Xu X, Dockery DW, Christiani DC, Li B, Huang H: Association of air pollution with hospital outpatient visits in Beijing. Arch Environ Health 1995, 50:214-220.

31. Xu X, Gao J, Dockery DW, Chen Y: Air pollution and daily mortality in residential areas of Beijing, China. Arch Environ Health 1994, 49:216-222.

32. Qian Z, He Q, Lin HM, Kong L, Liao D, Dan J, Bentley CM, Wang B: Association of daily cause-specific mortality with ambient particle air pollution in Wuhan, China. Environ Res 2007, 105:380-389.

33. Wong TW, Lau TS, Yu TS, Neller A, Wong SL, Tam W, Pang SW: Air pollution and hospital admissions for respiratory and cardiovascular diseases in Hong Kong. Occup Environ Med 1999, 56:679-683.

34. Ma M, Guo SQ, Wang SG: Analysis of the characteristics of air pollution and its boundary layer structural effect in recent 11 years over Lanzhou. Journal of Lanzhou University (Natural Sciences) 2012, 6:69-73.8.

35. Wang BJ, Xu DB, Pu YL, Wang PX, Wang XW: A study on synoptic cause of Air pollution and forecast methods of Air pollutant concentrations in Lanzhou proper in winter. GANSU METEOROLOGY 2001, 4:18-21.

36. Wang SG, Zhang L, Chen $\mathrm{CH}$, Yuan JY: Retrospect and prospect for the studies of atmospheric environment in the Lanzhou area. J Lanzhou Univ (Nat Sci) 1999, 3:189-201

37. Zhao J, Wang $\mathrm{N}: \mathrm{R} / \mathrm{S}$ analysis of urbanization effect on climate in Lanzhou. Arid Land Geography 2002, 25:90-95 (in Chinese).

38. Dockery DW, Pope CA: Acute respiratory effects of particulate air pollution. Ann Rev Public Health 1994, 15:107-132.

39. CIESIN and CIAT: 2005: 'Gridded Population of the World (GPW), Version 3', Center for International Earth Science Information Network, Columbia University and Centro Internacional de Agricultura Tropical, Palisades, NY. CIESIN. Palisades, NY: Columbia University. Available at http://sedac.ciesin columbia.edu/gpw.

40. Small C, Nicholls RJ: A global analysis of human settlement in coastal zones. J Coast Res 2003, 19:584-599.

41. Yang $X$, Huang $Y$, Dong $P$, Jiang D, Liu H: An updating system for the gridded population database of china based on remote sensing, GIS and spatial database technologies. Sensors 2009, 9:1128-1140.

42. Hastie T, Tibshirani R: Generalized Additive Models. Inc: Chapman and Hall 1990:355.

43. Hastie T, Tibshirani R: Generalized additive models (with discussion). Stat Sci 1986, 1:297-318.

44. Wood S: An Introduction with R. Chapman \& Hall/CRC, Generalized Additive Models. Press, Boca Raton, FL; 2006:391.

45. Morgan G, and Coauthors: The effects of low level air pollution on daily mortality and hospital admissions in Sydney, Australia, 1994 to 2000. Epidemiology 2003, 14:111-112.
46. World Health Organization: WHO Air Quality Guidelines:Global Update 2005 [C]. Bonn, Germany: WHO Working Group Meeting; 2005:18-20.

47. Hou Q, An, Y XQ, Wang J, Guo P: An evaluation of resident exposure to respirable particulate matter and health economic loss in Beijing during Beijing 2008 Olympic games. Science of The Total Environment 2010, 19:4026-4032.

48. Wei Y, Pan F, Wang J, Nu L: Relation of severe TSP pollution and natural dustfall in Lanzhou city. JOURNAL OF DESERT RESEARCH 2006, 5:763-766.

49. Yu Y, Xia DS, Chen LH, Liu N, Chen JB, Gao YH: Analysis of particulate pollution characteristics and its causes in Lanzhou, northwest china. ENVIRON SCI 2010, 1:22-28.

50. Choi J, Fuentes M, Reich BJ: Spatial-temporal association between fine particulate matter and daily mortality. Computation Statistics and Data Analysis 2009, 53:2989-3000.

doi:10.1186/1471-2458-13-891

Cite this article as: Sun et al.: Assessment of population exposure to PM10 for respiratory disease in Lanzhou (China) and its health-related economic costs based on GIS. BMC Public Health 2013 13:891.

\section{Submit your next manuscript to BioMed Central and take full advantage of:}

- Convenient online submission

- Thorough peer review

- No space constraints or color figure charges

- Immediate publication on acceptance

- Inclusion in PubMed, CAS, Scopus and Google Scholar

- Research which is freely available for redistribution

Submit your manuscript at www.biomedcentral.com/submit
C Biomed Central 